\title{
OS IMPERATIVOS DO BRASIL NO DESAFIADOR ESPAÇO REGIONAL DA AMÉRICA DO SUL: UMA VISÃO DA ECONOMIA POLÍTICA INTERNACIONAL*
}

Diana Tussie

Nos anos 1960, quando havia uma espécie de renascimento da construção regional, o economista Gunnar Myrdal fez uma advertência, sugerindo que a abordagem regional não tinha justificativa intrínseca. Não existem qualidades místicas em proximidades geográficas que façam nações vizinhas se transformarem em "unidade" em qualquer sentido real, seja do ponto de vista cultural, político ou econômico (Myrdal, 1968, p.39). Em outras palavras, as regiões têm de ser construídas de acordo com as necessidades e circunstâncias. Com a liberalização do comércio no âmbito de reformas neoliberais, acordos regionais foram arquitetados para "travar" reformas estruturais. Seguindo esse ponto de vista, o regionalismo e a globalização foram intrinsecamente interligados em uma relação de causalidade. Nessa relação, o regionalismo foi muitas vezes visto como subordinado aos ditames e às limitações da globalização ou, na melhor das hipóteses, como forma de aumentar o poder de barganha.

"Este artigo, "The imperatives of Brazil in a challenging South American regional space: a view from international political economy", foi traduzido por Florencia Mendes Ferreira Costa. 
A crise financeira mundial reformulou a ordem entre esses fatores, indo do nível global para o regional. Porém, mesmo antes de 2008, a articulação do espaço regional já havia se tornado central para os negócios, para os movimentos da sociedade civil e para as linhas gerais da política externa (Serbin, 2012; Trucco e Tussie, 2010). Qualquer que seja o ponto de vista, a América do Sul tornou-se uma plataforma pronta para um novo gatilho da construção regional, afastando-se da integração comercial dos tempos neoliberais, para outros projetos e usos regionais. Um espaço para a ação foi aberto. Porém até onde podemos discernir de verdade uma inédita governança regional, num momento que o comércio deixou de ser a cola e, de fato, acaba sendo muitas vezes o foco de conflitos comerciais? Um regime de comércio pós-regional é viável? O que sabemos sobre esses processos e os novos termos da política que são simultanea244 mente regional e nacional?

Em dezembro de 2011, o Centre for Economics and Business Research mostrou que a economia brasileira havia superado a do Reino Unido em 2011, tornando-se a sexta maior do mundo. Muito se fala desse marco. A ascensão para a primeira camada de países em desenvolvimento, que passaram a ganhar assim o status de economias emergentes, o inclui em uma categoria objetivamente diferente do amplo grupo de países em desenvolvimento.

Como resultado, não só o hemisfério, mas o sistema político internacional e a estrutura da economia global estão em estado de mudança contínua. A ascensão e queda de Estados abalam os pilares da ordem internacional. Essa é uma questão central para a economia política internacional, é um novo problema em termos de imperativos e desafios para os países não centrais. Uma das grandes dificuldades ainda enfrentadas por esses países emergentes e no Brasil, em particular, é como gerir essa ascendên- 
cia e ao mesmo tempo não ignorar as demandas sociais, como a necessidade de reduzir a pobreza e os altos níveis de desigualdade de renda, inconsistentes com sua nova dimensão e presença internacional. O Brasil é o gigante da América do Sul. Dentro do contexto de mudanças contínuas por que passa o hemisfério, com o declínio da hegemonia dos Estados Unidos nas relações interamericanas, a emergência do Brasil levanta a questão de até que ponto o país tem sido capaz de traduzir sua predominância em recursos instrumentais para organizar e liderar a região. Para muitos, trata-se de uma potência relutante (Spektor, 2009): os seguidores regionais nem sempre se alinharam com os principais objetivos da política externa do Brasil. No Pacífico, alguns governos ainda representam desafios abertos, como fica claro com a criação da Aliança do Pacífico, em maio de 2013. Muitos estudiosos afirmam que o objetivo do desenvolvimento econômico se sobrepõe à hegemonia regional (Vigevani e Cepaluni, 2009). A tensão entre a busca pelo poder e a pelo desenvolvimento reforça políticas pragmáticas para a integração regional. A partir dessa perspectiva, surge a questão da liderança e do papel do Brasil como um "líder relutante". O regionalismo é um imperativo estratégico?

Boa parte do debate sobre essas questões foi focada no Mercosul ou ficou restrita a estudos de política externa, esta última consumida pelos pressupostos realistas - tímidos para desvendar o nexo potência dos negócios. Essa união de interesses empresariais com a política externa continua a ser feita. Ela é relevante para compreender as transformações que ocorrem nos diferentes espaços da ordem internacional. Há um trabalho importante a ser feito sobre as relações entre as duas vertentes da literatura, as iniciativas dirigidas pelo mercado ou baseadas no mercado que abrem novos desafios e as formas de cooperação, como o Estado apoia e reage a esses incentivos e as implicações de 
poder estratégico, tanto no nível regional quanto global, que são típicos de estudos de política externa. Por um lado, existe a possibilidade de reforço mútuo, como a maneira pela qual países como o Brasil têm tentado preservar espaços para interesses privados, como ocorre com o aumento da construção de coalizões na OMC [Organização Mundial do Comércio], ou de cooperação estratégica com as ONGs [organizações não governamentais] na campanha para resistir às empresas multinacionais que utilizam direitos de propriedade intelectual para restringir o acesso ao tratamento barato do HIV.

Aqui quero focar as bases econômicas e questionar se essas criam uma demanda de alcance regional e global da política externa. Com uma perspectiva integradora, quando se pensa em Estados, também se pensa em Estados e mercados díades. Quais são os interesses que circulam dentro dessa nova perspectiva? Se o debate sobre a 246 construção regional significa ir além de uma construção narrativa, precisamos criar mais espaços para os incentivos que dirigem os atores, especialmente aqueles que estão se tornando cada vez mais integrados nas trocas globais. Em outras palavras, não é apenas o tamanho do país que importa, mas a intensidade e o conteúdo da integração na economia regional e mundial que importam no momento da construção regional.

Este artigo está estruturado em quatro seções. Na primeira, analiso como a economia política pode (ou deve) contribuir para o debate sobre o poder e a liderança em um hemisfério em mudança contínua. Na segunda, discuto como alguns indicadores são aplicáveis aos interesses do Brasil, como uma potência em ascensão. Na terceira, avalio a internacionalização das empresas brasileiras na região. $\mathrm{Na}$ última, discuto o que essas tendências podem significar em termos de construção regional. 


\section{Poder e liderança: como a economia política internacional pode contribuir?}

Dois modelos clássicos conseguiram enquadrar o debate sobre o poder econômico e de liderança. Em suas análises históricas, Charles Kindleberger (1986) proporciona um contraste entre as lideranças britânica e dos Estados Unidos e conecta dinheiro/finanças com bens públicos. Líderes fornecem bens públicos disponíveis para garantir a estabilidade. "Bens públicos internacionais são produzidos, em sua totalidade, pela principal potência, o chamado 'hegemon'" (Kindleberger, 1986, p.13) ${ }^{1}$. O hegemon é, simultaneamente, um estabilizador (que fornece um mercado para bens difíceis, um fluxo constante de capital e um mecanismo de redesconto para fornecer liquidez em momentos de pânico). Essa é a contribuição de Kindleberger sobre a noção de bens públicos em eixos de poder econômico. Os países menores não podem aspirar à vanguarda, pois eles não têm poder econômico e também não têm responsabilidade sobre todo o sistema. Eles apenas tiram proveito. Esse ponto de vista de autossacrifício do líder era um pilar de muita teorização sobre o papel dos Estados Unidos e sobre sua responsabilidade nos assuntos mundiais. Todos os outros países e aspirantes a líderes foram sempre deficientes com relação à prestação de bens públicos e à sua liderança.

Strange (1975), ao contrário, não se preocupou muito com a liderança, mas fez cuidadosa distinção entre o poder relacional e o poder estrutural. Poder relacional estava, acima de tudo, relacionado à capacidade de liderar e extrair determinados cursos de ações dos aliados e concorrentes. Porém o poder estrutural é mais importante. Opera em quatro níveis: o conhecimento, a segurança, as finanças e o

\footnotetext{
${ }^{1}$ Esse aspecto da teoria da estabilidade hegemônica teve enorme influência na disciplina e além dela, especialmente nos Estados Unidos. Para uma crítica que se aplica ao GATT, ver Tussie (1991), Wiener (1995).
} 
comércio. Assume o poder dos Estados e o papel das empresas transnacionais. De acordo com seu conceito, o poder econômico é exercido de forma espiral (Strange, 1975):

- Governos exercitam o poder econômico por meio da regulação e não regulação de mercados.

- Países ricos e seus governos influenciam a estrutura da economia global pelo padrão de seus investimentos, produção, comércio e consumo.

- Eles estabelecem a moldura para normas mínimas de manutenção da estabilidade, da ordem e da lei na economia de mercado global.

- O governo com o maior mercado interno e o maior número de empresas multinacionais (importante na condução da produção global) possui o maior poder econômico.

Mas em States, rival firms, competition for world market 248 shares, Stopford e Strange (1991) trazem muito mais informações para entender o nexo entre Estados e mercados. Tratam, principalmente, da mudança estrutural provocada pela internacionalização da produção e suas implicações para os países em desenvolvimento. O livro chama a atenção para as estruturas e influências da economia política de cada país. A questão sobre como a produção internacionalizada muda políticas e os processos de negociação entre os governos anfitriões e empresas estrangeiras foi levada adiante. O livro é baseado em estudos de caso do Quênia, Malásia e Brasil. Além do foco de dependência (mas não muito longe disso), o livro mostra as implicações da participação no mercado internacional e da pressão que a globalização coloca nos países para competir uns aos outros.

Essas novas estruturas trazem mais atores para o mercado, uma vez que dois Estados e suas empresas serão obrigados a participar. Embora Estados e mercados não 
possam andar de mãos dadas, eles vão competir juntos nos mercados mundiais. Países e empresas são obrigados a buscar mercados no exterior, para serem capazes de recuperar e manter lucros e investimentos. Política externa e diplomacia devem mudar, pois os Estados têm de negociar com empresas que colocam a produção em seu território, enquanto eles também convencem as empresas nacionais a tirar proveito dos mercados mundiais. O mercado internacional não é mais um porto seguro das corporações transnacionais norte-americanas.

A natureza da intervenção estatal eficaz também mudou: já não é mais sobre governar os negócios (ou mercados) e sobre negociação. É sobre a oferta de colaboração de negócios, estabilidade e condições favoráveis. Com os países melhorando suas posições no mercado global, eles também internacionalizam suas fronteiras e a estendem como um subproduto do seu poder estrutural. O nível regional de análise adiciona uma dimensão interessante para o estudo da economia política internacional, que, por muito tempo, foi mais focada em países e sociedades ocidentais. Visões de mundo dos governos e suas políticas refletem a geografia tanto quanto qualquer outra coisa. Enquanto impérios europeus, por um lado, mantêm ao mesmo tempo a balança de poder e o supranacionalismo tardio, os Estados Unidos, por outro, preservam a doutrina Monroe e a Área de Livre Comércio das Américas (Alca), e a maioria dos outros países também cria formas, talvez menos doutrinárias, de lidar com os vizinhos. Vou tentar desfazer e desconstruir o modo como o nexo potência dos negócios interage no caso do Brasil.

$\mathrm{O}$ apetite da China por matéria-prima, o apoio da Índia à tecnologia da informação e aos serviços são conhecidos por todos, mas os estudos sobre o Brasil permanecem consumidos pelo realismo e são tímidos em desvendar o nexo potência dos negócios. Esses estudos ainda estão para serem 
feitos e são relevantes para comparar potências emergentes e mostrar quais rachaduras e buracos podem estar surgindo nas hierarquias arraigadas, questão por questão, ou região por região.

\section{0 risco dos pés de barro: um conto dos grandes, mas não dos mais ricos}

Esta não é a primeira vez que surge a vocação de grandeza do Brasil. O Brasil esteve em alta entre os chamados países recém-industrializados na década de 1970. O desempenho do crescimento era então tão impressionante que chegou a ser apelidado de "o milagre brasileiro". Porém, no final da década, os preços do petróleo triplicaram, de mãos dadas com as altas das taxas de juro, uma reversão súbita dos fluxos de capital e uma queda acentuada na demanda por commodities, resultando em um choque externo triplo. O impacto sobre o balanço de pagamentos

250 foi devastador, a crise da dívida e a hiperinflação levaram a políticas ortodoxas, que buscavam suprimir a importação e restringir a demanda.

O milagre brasileiro foi desfeito e o Brasil entrou para as fileiras dos grandes devedores. O fim da Guerra Fria, na década de 1990, acabou produzindo duas outras práticas de conversão de potências regionais, então conhecidas como potências extras do hemisfério, capazes de construir alianças globais. Por razões diferentes, Argentina e México, ambos aspirantes, saíram frustrados. Ao mesmo tempo, o Chile, visto como um definidor de tendências, fez incursões em investimentos intrarregionais no transporte aéreo, serviços de varejo e fornecimento de energia. Mas, apesar da percepção generalizada de que o Chile era um garoto-propaganda, sua internacionalização não aumentou muito sua influência regional.

O tamanho, porém, importa. O Brasil tem dimensões continentais: um terço do território, da população e do PIB 
da região. O que é ainda mais importante no novo contexto global é a crescente internacionalização, sem precedentes, de negócios no Brasil e o papel do país como o principal investidor intrarregional. Essas características fazem uma diferença especial em tempos de mudança de poder no mundo. Enquanto o país passa a ser um exportador de capital, já não precisa mais dos favores do conselho do FMI ou do Tesouro dos Estados Unidos.

A acomodação de interesses empresariais brasileiros à política econômica externa levou a duas vertentes de abordagens. No nível global, a uma promoção ativa do agronegócio nas negociações da OMC, a formação do G20 em 2003, e ao ativismo jurídico na resolução de litígios em defesa das exportações. No nível regional, o Brasil fez progressos para reconfigurar o espaço sul-americano distinto da ampla América "Latina". A redefinição regional tem sido uma característica importante na economia política do hemisfério na última década, deixando assim o México fora ou com um alcance apenas na América Central e no Caribe, feito relativamente fácil após o colapso do Grupo dos Três (México, Venezuela e Colômbia). Em 2000, Brasília convidou todos os chefes de Estado da América do Sul para a primeira cúpula do tipo e mais tarde promoveu a fusão entre o Mercosul e a Comunidade Andina de Nações para lançar uma Comunidade Sul-Americana de Nações. A declaração presidencial sul-americana que surgiu dessa reunião levou à criação da Iniciativa para a Integração da Infraestrutura Regional (IIRSA) (Carciofi, 2012; Saguier 2012). Essa operação teve alguns objetivos. $\mathrm{O}$ primeiro, enterrar definitivamente o pan-americanismo liderado pelos Estados Unidos, substituindo-o por um processo mais gerenciável de construção regional, já que a América do Sul tem laços econômicos mais fracos com os Estados Unidos do que a parte norte do continente. O segundo objetivo foi excluir o México de uma poten- 
cial concorrência de liderança na região. Muito ligada a tudo isso foi a ideia de criar e preservar uma plataforma de um florescente negócio brasileiro na infraestrutura da região. A IIRSA tornou-se uma ferramenta-chave do Brasil para estabelecer o conjunto de suas políticas para a América do Sul. O presidente Lula, em seguida, levou adiante essa estratégia, resultando na criação da Comunidade Sul-Americana na cúpula presidencial Cuzco em dezembro de 2004. O nome mais tarde tornou-se a União das Nações Sul-Americanas (Unasul), cujo tratado constitutivo foi assinado em Brasília em maio de 2008.

No entanto, o desempenho social do Brasil é pobre, em contraste com o alcance dos negócios na região. No relatório de Desenvolvimento Humano 2013, o Índice de Desenvolvimento Humano (IDH) do Brasil coloca o país em $85^{\circ}$ lugar de um total de 187 países. A colocação é compartilhada com a Jamaica. O IDH é elaborado com 252 base em uma combinação de dados sobre educação, saúde e renda per capita. Embora o Brasil tenha desempenho médio melhor do que o dos países do BRICS [Brasil, Rússia, Índia, China e África do Sul] e do IBAS [Índia, Brasil e África do Sul] no IDH, a classificação praticamente se inverte quando levamos em consideração outros países sul-americanos. O Brasil é também um dos países mais desiguais do mundo. Se levarmos em conta o índice de Gini, que mede o grau de desigualdade na distribuição de renda, o Brasil ocupa a oitava posição no ranking geral. Isso significa que as mãos do país estão atadas com relação à provisão de bens públicos regionais. Sem um novo contrato social, transferências para países vizinhos estão fora de questão. A ebulição social em uma série de cidades brasileiras em junho de 2013 é uma evidência nesse sentido. Com indicadores sociais fracos, o Brasil permanece, por força, como escasso provedor de bens públicos regionais (o modelo Kindleberger). No entanto, o país mostra for- 
te projeção de negócios no exterior (o modelo Strange). Diante de queixas generalizadas, o que se tornou claro é que a expansão econômica no exterior exige um contrato social de apoio em casa para manter a coesão social. Peter Katzenstein (1985) argumenta que as pequenas economias abertas da Europa desenvolveram instituições corporativistas para facilitar a adaptação, a cooperação econômica capital-trabalho e os sistemas de segurança social compensatórios. Políticas de bem-estar social são o capital de custo para a expansão econômica em democracias.

A discrepância entre o desempenho social e o peso econômico regional (ou alcance) não impede outros países de ver o Brasil como uma potência regional ou uma "nova potência influente" (Soares e Hirst, 2006). A influência decorre da atração que o país pode exercer, como resultado de uma população relativamente grande e uma área de terra que desempenha papel dominante no comércio dentro da região e na governança regional. O poder regional é capaz não só de atrair IED [investimento estrangeiro direto], mas também de apoiar suas empresas a agir regionalmente e com força crescente, em nível mundial.

O Brasil hoje participa, sem dúvida, do desenvolvimento de normas e padrões técnicos e econômicos, de segurança internacional, em missões em regiões de conflito, em políticas climáticas e de energia (Viola, Franchini e Ribeiro, 2012), e em questões relacionadas com a reforma monetária e com a gestão econômica no mundo. A expansão da economia brasileira deu à América do Sul um estímulo mensurável e oportunidades de alinhamento ao papel do Brasil. A região também se beneficia de um acesso melhor e mensurável às questões globais. Vizinhos menores percebem o Brasil como um centro de poder com o qual devem se alinhar precisamente porque não estão dispostos a se tornar uma força de policiamento regional. 


\section{Internacionalização dos negócios: um pilar para 0 compromisso regional}

Tomada como um todo, a literatura sobre política externa na região tem se dedicado muito pouco ao aspecto de como os negócios são ajudados na grande estratégia assim como nos processos de condução para o exterior. Isso leva a um ponto cego nos microfundamentos da ação política. Um dos argumentos deste artigo é que os interesses estratégicos dos Estados merecem mais iluminação e que, embora tenha havido ampla pesquisa sobre como os negócios influenciam a política externa das grandes potências ${ }^{2}$, essa aproximação a ser feita é de particular relevância no caso de potências emergentes como o Brasil. Todas as potências emergentes enfrentam dificuldades de diferentes tipos à medida que se expandem no exterior. Expansão no exterior é uma consequência da gestão perspicaz da relação Estado-empresa.

$254 \quad$ Um dos principais pontos fortes do Brasil encontra-se na internacionalização de suas empresas e no apoio dado pelo Estado para essas atividades. A Vale, que produz $15 \%$ do minério de ferro mundial, é a segunda maior mineradora do planeta. Os atores globalizados brasileiros são da indústria de alimentos: a JBS Friboi (maior empresa do mundo no setor de carne bovina), os serviços de construção (Odebrecht, Andrade Gutierrez, Camargo Correa), aço (Gerdau), serviços financeiros (Banco do Brasil, Itaú) e indústrias extrativistas (Petrobras, Vale). Essas empresas são atores poderosos em assuntos globais, mas em particular na política de poder da região, onde a maioria dos seus interesses é implantada e onde exercem sua influência em vários campos, de diversas maneiras e com diferentes resultados.

\footnotetext{
${ }^{2}$ Em contraste com outros estudiosos, Frieden (1988), Stopford e Strange (1991) situam grupos de interesse no centro da política. Frieden argumenta que a posição internacional de investimento de um país tende a afetar suas preferências econômicas internacionais de maneira facilmente compreendida e antecipada.
} 
Porém a política econômica externa e a geopolítica não podem ser fundidas de forma simples; os interesses comerciais não traduzem facilmente, de forma ordenada ou completa, o comportamento da política externa. No entanto, a administração dos presidentes Lula e Dilma Rousseff deu continuidade a uma política econômica extremamente ortodoxa em casa (com reforço considerável da política social), enquanto pressionou por uma mudança mais radical no exterior. Os críticos observaram que uma das características marcantes do governo Lula foi que ele tinha sido muito mais radical em sua política externa e nas suas denúncias dos descontentamentos da globalização do que foi na sua ortodoxa política macroeconômica interna.

O Brasil tem, de fato, sido mais assertivo no estabelecimento da credibilidade política e econômica internacional em questões regionais e muito particularmente na OMC. Hurrell e Narlikar (2006) argumentam que as consultas com os grupos de interesse têm, no máximo, desempenhado papel de reforço. Pressões comerciais são seletivas, podem exercer impacto apenas em áreas de nicho limitadas, e muitas vezes servem como dispositivos para legitimar as posições políticas e negociações que os governos adotam internacionalmente. Soares e Hirst (2006, p.21) ressaltam que "o desejo do Brasil de influenciar as regras e regimes internacionais, e de ser considerado um grande jogador, tem sido entendido principalmente em termos de poder brando (soft power)". $\mathrm{O}$ poder brando baseia-se na diplomacia e molda instituições ao determinar agendas. Baseia-se na disseminação de valores (Ayllón e Costa Leite, 2010). O Brasil aplicou esse tipo de poder. Reivindicações de mobilização para maior equilíbrio de representação (como com membros do Conselho de Segurança) e da justiça distributiva (como acontece com a promoção de um fundo de fome mundial ou de saúde relacionados com renúncias de propriedade intelectual) são vistas como fundamentais para essa tarefa. Elas também 
são retratadas como a face externa do compromisso social interno do governo.

Enquanto Malamud (2012) desafia essa suposição de poder brando em nível mundial, também merece ser desafiado o ponto de vista da política comercial como mera low politics. O comércio é mais do que uma boa impressão para os técnicos. A política comercial pode aceitar e desafiar a ordem, que, por sua vez, pode aceitar ou desafiar a distribuição. $\mathrm{Na}$ década de 1990, quando a governança da economia política regional estava em jogo, as questões comerciais tornaram-se as mais importantes. Para a governança regional, a execução da fratura da Alca, especialmente após a Cúpula das Américas, em Belo Horizonte, em 1997, foi um divisor de águas. Não só o presidente Fernando Henrique Cardoso deixou claro que os acordos sub-regionais não poderiam ser diluídos na Alca, como também o evento foi um ponto de virada para a influência dos negócios brasileiros.

256 A cúpula de líderes de governo incluiu uma reunião paralela, um Fórum Empresarial da Alca reunindo chefes de Estado com líderes do empresariado que discutiram propostas do setor de negócios. As reuniões da Alca ajudaram a desencadear a criação de uma parceria oficial entre os setores industrial e agrícola do Brasil sob uma nova e abrangente Coalizão Empresarial Brasileira. A Coalizão era uma novidade institucional, não só porque reuniu diferentes setores, rompendo com a tradição setorial do Brasil de articulação de interesses, mas também porque induziu os negócios a focar um único tema: as negociações comerciais (Motta Veiga, 2002). A Coalizão reúne 166 associações e empresas brasileiras sob um único guarda-chuva, incluindo a Confederação Nacional da Indústria (CNI), a Confederação Nacional da Agricultura, a Confederação Nacional do Comércio, federações de indústrias de diferentes estados, como a Federação das Indústrias do Estado de São Paulo (Fiesp), sindicatos de empregadores, como a Força Sindical, e associações setoriais 
específicas. A CNI assumiu a liderança dentro da Coalizão; na reunião ministerial subsequente, em Buenos Aires, em 2001, a delegação brasileira finalmente rejeitou a proposta dos Estados Unidos de antecipar o prazo para a conclusão de uma Alca.

Como resultado da mobilização em torno das negociações da Alca, o governo criou no Itamaraty um canal especial, a Secretaria Nacional da Alca (Senalca) para um diálogo com as principais câmaras de comércio e organizações da sociedade civil, como os sindicatos da Central Única dos Trabalhadores (CUT). A estrutura foi emulada para as negociações com a União Europeia (UE), sob o nome de Seneuropa. Isto é o que Vigevani e Cepaluni (2009) definem como a "busca da autonomia por meio da participação”.

Como observou Schneider (2004), os executivos tendem a se interessar especialmente por suporte e agregação quando eles estão no meio de iniciativas arriscadas para mudar as estratégias gerais de desenvolvimento e invocam as associações empresariais para prestar vários tipos de assistência, a começar por tarefas muito simples, como a obtenção de mais informações sobre o setor da economia que é o objeto de elaboração de políticas. Claramente, então, há um lado da política doméstica para a política comercial, uma relação de "ancoragem", como diz Bianculli (2010) apropriadamente. Aos poucos, a área econômica do Itamaraty ganhou relevância, tanto em termos de números como de influência.

Desse modo, não é exagerado afirmar que o empresariado se converteu em um interlocutor privilegiado do Estado no que diz respeito à integração regional e à política de negociações comerciais durante os mandatos do presidente Fernando Henrique Cardoso, de 1995 a 2002 (Epsteyn, 2010).

$\mathrm{O}$ segundo ponto de virada veio quando o governo Lula assumiu o poder, com a ênfase muito acentuada nas relações com a América Latina, com o Mercosul, 
mas cada vez mais com a América do Sul como um todo. Celso Amorim, ministro das Relações Exteriores de Lula, foi claro outra vez ao afirmar que a "América do Sul é uma prioridade estratégica” (Amorim, 2004). A centralidade da dimensão latino-americana representa importante diferença entre a política externa brasileira de hoje e sua política externa terceiro-mundista na década de 1970, quando o Brasil, em geral, se manteve distante da região. O Mercosul já não seria mera plataforma para aumentar o poder de negociação com o mundo, mas a fortaleza para ganhar credibilidade e orientar pressões externas. No novo clima político, o governo intensificou relações com [Néstor] Kirchner, [Hugo] Chávez, [Evo] Morales e abriu espaço para redes da sociedade civil e sindicatos, mas os negócios não foram negligenciados.

Seguindo o padrão argentino em 2001, enquanto o investimento estrangeiro direto norte-sul caiu, os investidores bra258 sileiros adquiriram uma série de ativos argentinos. Em maio de 2002, a AmBev, líder na produção de bebidas, anunciou planos para comprar um terço da principal fabricante de cerveja da Argentina, Quilmes, negócio avaliado em US\$ 700 milhões. Esse foi o primeiro grande investimento estrangeiro na Argentina após o default de 2001. Naquele mesmo ano, a Petrobras comprou o controle acionário da Pérez Companc por cerca de US\$1,1 bilhão. Na tentativa de enfrentar os dilemas da Realpolitik e evitar o confronto aberto com poderosos interesses comerciais estabelecidos, os canais institucionais como Senalca ou Seneuropa desapareceram e foram substituídos por acessos privilegiados e informais. Enquanto think tanks como Ícone (representando o agronegócio) ou Cebri (fortemente apoiado pelos grandes exportadores) tentaram promover uma visão cosmopolita no Brasil; na ausência de intermediação privilegiada feita por associações, houve fortes incentivos para o lobby individual. Os contatos cada vez mais estreitos com as empresas de energia e construção com for- 
tes interesses regionais foram favorecidos em detrimento de outros, como um proeminente industrial resumiu: "Eu não preciso da Fiesp. Posso chamar quem eu quiser no governo" (citado por Schneider, 2004). Shaffer, Rosenberg e Ratton Sanchez (2008) fornecem provas detalhadas de como as parcerias entre governo e empresas foram fundamentais para a formação de políticas de comércio e para a solução de controvérsias na OMC.

O programa foi iniciado em 2003. Dois anos depois, foi expandido para incluir estagiários das maiores associações industriais do Brasil, como Fiesp e CNI. Os autores também apontam que os departamentos universitários e as ofertas de cursos mudaram significativamente na última década, em resposta ao elevado interesse comercial e ao aumento do foco da política brasileira em assuntos relacionados com o comércio como uma preocupação estratégica.

O Banco Nacional de Desenvolvimento Econômico e Social (BNDES) criou uma linha de crédito especial em 2002 para apoiar o IED no exterior, linha essa concedida com a condição de que em seis anos os beneficiários aumentassem as exportações a uma proporção igual ao crédito oferecido. Esse instrumento foi utilizado pela primeira vez pela Friboi em 2005 para comprar a Swift na Argentina. Alguns dos projetos no âmbito da IIRSA e do Fundo para a Convergência Estrutural do Mercosul (Focem) ficaram sob a responsabilidade do BNDES. O portfólio do BNDES soma 55 bilhões em empréstimos, maior do que o portfólio do Banco Mundial e do Banco Interamericano na região.

É dentro desse quadro que o Brasil apoia os seus negó$\operatorname{cios}^{3}$. Uma das medidas da Política Industrial Tecnológica

\footnotetext{
${ }^{3}$ A taxa de juros sobre créditos à exportação oferecida pelo BNDES para a Embraer foi objeto de prolongada disputa comercial entre Brasil e Canadá, que defendendo a empresa de construção Bombardier (Goldstein e McGuire, 2004). Sobre a importância de créditos à exportação como um instrumento central da política comercial estratégica, ver Ferreira (1997).
} 
e de Comércio Exterior lançada em março de 2004 foi a criação de 38 unidades de comércio externo multidimensionais dentro do Banco do Brasil para apoiar a internacionalização das empresas nacionais (Goldstein, 2009). Embora a América do Sul tenha sido a região preferida, outras oportunidades não foram negligenciadas. Em novembro de 2005, o Programa de Incentivo aos Investimentos Brasileiros na América Central e no Caribe [Pibac] foi lançado para estimular o investimento brasileiro na América Central e para beneficiar o CAFTA-DR, o acordo de livre-comércio entre a América Central e os Estados Unidos. Nas palavras de Alcides Costa Vaz (2007, p.34):

O protagonismo brasileiro [...] é interpretado politicamente como uma expressão de expansionismo econômico, sobretudo quando o envolvimento do Banco Nacional de Desenvolvimento Econômico e Social e [...] o desempenho

260 das grandes empresas de construção civil e da Petrobras estão em jogo.

A construtora Odebrecht é uma participante importante na maioria dos projetos do BNDES na América do Sul, sendo a principal beneficiária dos contratos da IIRSA até agora ${ }^{4}$. A imagem da América do Sul e o conteúdo do regionalismo foram alterados com o fluxo de capitais brasileiros expandindo-se rápido, especialmente no setor da construção e energia (Carciofi, 2012; Saguier, 2012). A holding Odebrecht, uma das três maiores empresas, representa o primeiro exemplo de multinacional favorecida pelas administrações recentes. Ela se situa em $16^{\circ}$ lugar na lista das principais empresas latino-americanas e opera em dezoito países de onde exporta para sessenta países. Quase três quartos da

\footnotetext{
${ }^{4}$ No início de 2012, a presidente Dilma Rousseff anunciou investimentos no porto de Cuba no valor de US\$800 milhões durante uma visita àquele país.
} 
renda (no braço de engenharia da empresa) da Odebrecht vem do exterior e $50 \%$ de sua força de trabalho reside em outros países, transformando-a na empresa brasileira mais internacionalizada. Parte significativa de sua expansão no exterior foi na Venezuela, onde participa de cinco grandes contratos, como construção de pontes, o metrô de Caracas, usinas hidrelétricas etc.

Como é de esperar, as relações podem azedar, e não só em casa, onde a concessão do estádio do Maracanã ficou sob fogo cerrado durante os protestos de junho que abalaram o país. Em setembro de 2008, o presidente Rafael Correa expulsou os gestores da Odebrecht, que ele acusou de suborno e de cometer falhas na construção de uma usina. Correa não só declarou que seu país não compensaria a empresa pelo que já havia construído, mas também se recusou a pagar o empréstimo de US\$ 243 milhões que o BNDES havia concedido ao Equador para essa finalidade. Um conflito semelhante ocorre entre o governo argentino e os investimentos interrompidos da Vale no país. Como apontado por Saguier (2012), a política de integração regional liderada pelos recursos é um processo sensível.

Em suma, a partir de um ponto de vista brasileiro, há uma base econômica para a expansão da atividade regional. Em uma estratégia conjunta, não desprovida de conflito, o governo e as empresas privadas têm interesses recíprocos e sobrepostos, embora não idênticos, na região. $\mathrm{O}$ argumento deste artigo é, portanto, que é preciso ver como as empresas se adaptam, como elas estão envolvidas na política e como os governos contam com empresas para esforços diplomáticos a fim de se compreender a estrutura especial de incentivos na política externa. No caso da regionalização brasileira, é importante ter em mente que, para boa parte de sua história, a identidade brasileira não foi baseada na ideia de "América Latina”, à qual não parece pertencer (Lafer, 2001; Quijada, 1998). 


\section{Desenvolvimento internacional sob instituições nascentes: novo estágio para a política externa}

A ascensão e o declínio da influência industrial e comercial dos Estados perturbam as relações econômicas internacionais. É evidente que tanto o Estado como as empresas têm sido intimamente envolvidos no processo de internacionalização. A internacionalização marca nova etapa do desenvolvimento: o internacional, que abre um terreno de cooperação entre Estados e empresas, afetando as próprias estruturas e processos de política externa. Os governos podem implementar suas capacidades organizacionais e estruturas políticas institucionais de forma estratégica para conduzir, levar, regular ou tirar proveito de interesses particulares. A solvência fiscal permite a concessão de crédito subsidiado central.

A missão do Banco dos BRICS e do Banco do Sul segue na mesma direção consciente do valor do crédito 262 de longo prazo como fonte de poder e financiamento de infraestrutura no exterior. $\mathrm{O}$ argumento deste artigo tem sido, portanto, o de que é preciso ver como as empresas se adaptam, como elas estão envolvidas na política e como os governos contam com elas para se estender no exterior. Indo além desse exercício, no estabelecimento de ambas as bases de especificidade e de material, a questão de quem está no assento do motorista em conjunturas específicas é bem outra: se é o governo tentando regular e orientar o mercado em busca de objetivos definidos do próprio governo ou a expansão de oportunidades de negócios com impacto sobre os objetivos do Estado.

A internacionalização de diferentes países exige a decomposição para fins de análise. Em cada país os caminhos seguidos são diferentes, tanto em termos de questões como na extensão até à qual o Estado conduz ou segue a tendência mais ou menos por força. Para alguns países, o principal interesse pode ser o acesso aos recursos naturais, 
para outros pode ser a redução dos custos trabalhistas ou a implantação de firmes vantagens específicas anteriormente adquiridas em casa.

Para o Brasil hoje, o impulso central encontra-se na competição por contratos governamentais de grande porte, especialmente em países que não abriram os seus mercados de contratos, como resultado de acordos de livre-comércio com os Estados Unidos ou com a União Europeia. A abordagem regional oferece às empresas um caminho para a expansão no exterior sob um grau de proteção contra esses concorrentes.

Grugel e Riggirozzi (2012) têm ressaltado que as expectativas que a governança regional podem oferecer à América Latina foram avaliadas principalmente em termos de acesso ao mercado e da geração de comércio entre os países. Enquanto Epstyen (2010) deixa claro que há um interesse limitado do Brasil na construção da região, Spektor (2009), Malamud (2012), Vigevani e Cepaluni (2009) discutem a ambivalência de atitudes brasileiras com relação à sua região e à fina arquitetura regional pela qual o Brasil tem demonstrado interesse até agora. Mas os interesses empresariais exigem envolvimento cada vez maior na região e crescente proficiência para resolver conflitos, engajamento que pode ou não vir com a construção de instituições de peso.

Por todas as suas deficiências, o engajamento econômico com os vizinhos tem um lugar de destaque na política externa brasileira, que é microgerenciada, principalmente, para defender interesses específicos. Por uma série de razões, como o risco de contestação de desafiantes como a Venezuela ou a Aliança do Pacífico e da indiferença do Chile, há uma preferência para lidar com os vizinhos em bases individuais, questão por questão, em uma quase emulação da estratégia articulada pela Representação dos Estados Unidos para o Comércio (USTR, na sigla em inglês) sob a 
liderança de Robert Zoelig. Quando a resistência coletiva à Alca ganhou força e foi capaz de parar o processo, Zoelig então ofereceu acordos bilaterais.

De fato, alguns argumentam que os interesses comerciais do Brasil, em um processo de internalização nascente, são mais bem atendidos ao não abrir mão de qualquer soberania para os órgãos regionais. A fim de preservar um ambiente mais dócil, o Brasil resiste ou responde seletivamente às chamadas para o aprofundamento das instituições regionais e para a prestação de bens públicos (à la Kindleberger). No entanto, o Brasil é cada vez menos indiferente à estabilidade dos vizinhos.

A estratégia regional do Brasil tem contado com a restrição do poder esmagador dos Estados Unidos. No entanto, como emerge um mundo pós-hegemônico e pós-Estados Unidos, algumas iniciativas começam a tomar forma. Enquanto na Ásia Oriental funciona o regionalis264 mo monetário, o Brasil o tem evitado, exceto em suas formas mais mornas, na medida em que não há cadeias de valores regionais que precisam de financiamento externo (Trucco, 2012). Mas a crescente infraestrutura regional de fronteiras não só conecta o continente, mas também promove iniciativas de segurança coletiva. Quando as tropas colombianas perseguiram e mataram integrantes das Forças Armadas Revolucionárias da Colômbia no Equador, em 2008, o ministro Nelson Jobim promoveu a ideia de patrocinar a segurança coletiva sob um Conselho de Defesa Sul-Americano, agora parte integrante da Unasul. O notável hoje é que as ações de condução e reação das forças primárias na política regional parecem em grande parte endógenas. Os atuais acordos regionais devem ser analisados como política nacional por outros meios.

O país finalmente parece perceber que o investimento no exterior exige promoção, proteção e antenas especializadas em política externa. Enquanto isso é, sem dúvida, uma 
verdade e, mais ainda, uma visão amplamente compartilhada que dispõe o Brasil a um senso de direito, ao mesmo tempo outras partes da região estão no mesmo estado de espírito triunfal. O status de uma potência regional é sempre desafiado como resultado do poder de negociação coletiva dos outros, seja por parte dos países dominantes, como os da União Europeia e os Estados Unidos, seja por parte dos concorrentes na região.

Hoje, a Aliança do Pacífico, que reúne México, Colômbia, Peru e Chile, destaca-se como uma força competitiva nos assuntos regionais. Isso aponta para um cenário em que as possibilidades de confrontos reais de interesses e de valores permanecerão amplas. É de fato aqui que vamos continuar a ver as mudanças mais profundas, como é demonstrado pelo anúncio da Colômbia, em junho de 2013, de que assinaria um acordo de cooperação com a Otan.

O dilema da política externa brasileira é como construir e manter um eleitorado regional, certificando-se da inclusão dos países da periferia. A chave para a maior parte deste artigo é a capacidade dos atores de resolver os seus problemas de modo coletivo e, em seguida, construir coalizões majoritárias. Nesse contexto, argumentamos que o Brasil tenta conquistar papel de destaque no palco mundial e que a sua emergência como potência mundial média não se traduz facilmente em ganhar a aceitação total como líder em sua região. A questão então é olhar para as possibilidades de consolidação do regionalismo sul-americano para tornar-se uma organização operacional baseada em interesses ou identidades comuns, um "objeto político identificado" para emprestar a frase de Jacques Delors em relação ao dilema da União Europeia em assuntos mundiais. A lição resultante da Europa é que as instituições regionais muitas vezes precisam de grandes Estados-membros com quadros tecnocraticamente capazes de proporcionar visão e liderança para o resto do grupo. A França e a 
Alemanha têm desempenhado esse papel na Comunidade Econômica Europeia; Singapura e Tailândia parecem aspirar a um papel semelhante de parceria na ASEAN (Associação de Nações do Sudeste Asiático). A Venezuela e a Aliança do Pacífico competem a partir de ângulos opostos com o Brasil para exercer esse papel em vários terrenos e com diferentes estilos para a institucionalização de novos projetos, como a Unasul, que ainda está longe de ser estável e que apenas canaliza a incerteza que surge com a competição. Muitas das iniciativas econômicas sob a Unasul, como os esforços para criar um banco ou promover a cooperação monetária, vêm do Equador ou da Venezuela, cujo entendimento da organização difere consideravelmente do do Brasil. A Argentina, por sua vez, tem cultivado excelentes relações tanto com o Brasil como com a Venezuela. Enquanto a Alba (Aliança Bolivariana para os Povos de Nossa América) reuniu Bolívia e Equador, Colômbia e 266 Chile são indiferentes a esses jogos de poder e, com Peru e México, se voltam em direção aos Estados Unidos e ao Pacífico (Quiliconi, 2013). Enquanto a América Central, o Chile, a Colômbia e o México encontram valor no mercado dos Estados Unidos, outros governos são mais desafiadores em uma variedade de maneiras, derivando a legitimidade política de sua capacidade de preservar a região como um espaço para nichos normativos.

O que vemos agora é um jogo circular de cooperação e competição, por meio de estruturas e arranjos regionais, cada um tentando ganhar credenciais regionais. Nesse contexto, muitos argumentam que o Brasil pode aspirar a um papel de liderança no cenário mundial se ele continuar sozinho. Mas, para as potências emergentes, em quase todos os casos, "as regiões fornecem a legitimidade que permitem às potências emergentes participar e proteger suas reivindicações no cenário global" (Nel e Nolte, 2010, p.878). Hoje, o Brasil pode ser visto na liga dos países globalizadores de 
estilo conciliador e alternativo. Mais do que em qualquer momento de sua história, o país voltou-se mais para o exterior a partir de uma perspectiva diplomática e de negócios. Como um exportador líquido de capitais para a região e, portanto, vulnerável ao risco político, ele mostra crescente valorização da estabilidade regional, catalisando os esforços diplomáticos, criando nichos normativos com espaço para moldar a forma como os problemas serão compreendidos. Não é o começo de um regionalismo econômico Pan-América do Sul, mas trata-se de um bom começo com uma base material, que precisa ser protegida e promovida.

\section{Diana Tussie}

é coordenadora do Departamento de Relações Internacionais da Flacso (Argentina), fundadora e diretora da Latin American Trade Network (LATN) e membro do Committee for Development Policy, das Nações Unidas.

\section{Referências bibliográficas}

AMORIM, C. L. N. 2004. Texto da Aula Magna proferida na Universidade Federal de Rio Janeiro em 12 mar. 2004. Disponível em: <http:/ /www.mre. gov.br/index.htm>. Acesso em: 12 jul. 2012.

AYLLÓN, B.; COSTA LEITE, I. 2010. "La cooperación sur-sur de Brasil: proyección solidaria y política exterior”. In: BRUNO, A.; SURASKY, J. (coords.). La cooperación sur-sur en América Latina: utopía y realidad. Madrid: Ediciones Cataratas.

BIANCULLI, A. C. 2010. Trade governance in Latin America. Interest articulation and institutions across negotiations in Argentina and Chile. Barcelona. Tese de doutorado. Universitat Pompeu Fabra.

CARCIOFI, R. 2012. "Cooperation for the provision of regional public goods: the IIRSA case”. In: RIGGIROZZI, P.; TUSSIE, D. (eds.). The rise of post-hegemonic regionalism. The case of Latin America. Heidelberg/ London/New York: Springer. pp. 65-80.

COSTA VAZ, A. 2007. "Brasil y sus vecinos: ¿del descubrimiento a la interdependencia?”. In: HOFMEISTER, W.; ROJAS, F.; SOLÍS, L. G. (eds.). La percepción de Brasil en el contexto internacional: perspectivas y desafíos. Rio de Janeiro: Konrad Adenauer Stiftung. pp.23-40. 
EPSTEYN, J. C. 2010. "El escenario regional como complemento al esceanrio regional”. In: TRUCCO, P.; TUSSIE, D. Nación y región en América del Sur: los actores nacionales y la economía política de la integración sudamericana. Buenos Aires: Editorial Teseo.

FERREIRA, M. I. 1997. The importance of export credits for the Brazilian economy. George Washington University, Institute of Brazilian Studies. Disponível em: <http://www.gwu.edu/ ibi/minerva/Spring1997/ Maria.Izilda.Ferreira/Maria.Izilda.Ferreira.html>.

FRIEDEN, J. 1988. "Capital politics: creditors and international political economy". Journal of Public Policy, v.8, n.3/4.

GOLDSTEIN, A. 2009. Multinational companies from emerging economies: composition, conceptualization and direction in the global economy. Palgrave Macmillan.

; McGUIRE, S. 2004. "The political economy of strategic trade policy and the Brazil-Canada export subsidies saga. The World Economy, v.27, n.4.

GRUGEL, J.; RIGGIROZZI, P. 2012. "Post neoliberalism: reclaiming and rebuilding the state in Latin America”. Development and Change, v.43, n.1, pp.1-21.

HURRELL, A.; NARLIKAR, A. 2006. "A new politics of confrontation?: Brazil and India in multilateral trade negotiations". Global Society, v.20, n.4, pp.415-33.

KATZENSTEIN, P. J. 1985. Small states in world markets: industrial policy in Europe. Ithaca, NY: Cornell University Press.

KINDLEBERGER, C. 1986. The World in Depression. Berkeley: University of California Press.

LAFER, C. 2001. A identidade internacional do Brasil e a política externa brasileira: passado, presente e futuro. São Paulo: Perspectiva.

MALAMUD, A. 2012. "Moving regions: Brazil's global emergence and the redefinition of Latin American borders". In: RIGGIROZZI, P.; TUSSIE, D. (eds.). The rise of post-hegemonic regionalism. The case of Latin America. Heidelberg/London/New York: Springer. pp.167-82.

MOTTA VEIGA, P. 2002. Trade policy making in Brazil transition paths. Disponível em: <http://www.sice.oas.org/ctyindex/ARG/ policymaking_e.pdf $>$. Acesso em: 7 jul. 2013.

MYRDAL, G. 1968. Asian drama: an enquiry into the poverty of regions. New York: Pantheon. v.1.

NEL, P.; NOLTE, D. 2010. "Introduction: special section on regional powers in a changing global order". Review of International Studies, v.36, pp.877-9. 
QUIJADA, M. 1998. "Sobre el origen y difusión del nombre 'América Latina' (o una variación heterodoxa en torno al tema de la construcción social de la verdad)". Revista de Indias, v.58, n.214.

QUILICONI, C. 2013. "Modelos competitivos de integración en el Hemisferio Occidental: ¿Liderazgo competitivo o negación mutua?”. Revista CIDOB d'Afers Internacionals, Barcelona, n.102-103, pp.14768, 26 set. Disponível em: <http://www.cidob.org/ca/publications/ articulos/revista_cidob_d_afers_internacionals/102_103/competitive_ integration_models_in_the_western_hemisphere_competitive_ leadership_or_mutual_denial>. Acesso em: 29 set. 2013.

RIGGIROZZI, P.; TUSSIE, D. (eds.). 2012. The rise of post-hegemonic regionalism. The case of Latin America. Heidelberg/London/New York: Springer.

SAGUIER, M. 2012. "Socio-Environmental Regionalism in South America: Tensions in New Development Models”. In: RIGGIROZZI, P.; TUSSIE, D. (eds.). The rise of post-hegemonic regionalism. The case of Latin America. Heidelberg/London/New York: Springer. pp.125-46.

SHAFFER, G.; ROSENBERG, B.; RATTON SANCHEZ, M. 2008. "The trials of winning at the WTO: what lies behind Brazil's success". Cornell International Law Journal, v.41, n.2.

SCHNEIDER, B. R. 2004. Business Politics and the State in XX century Latin America. Cambridge: Cambridge University Press.

SERBIN, A. 2012. "New regionalism and civil society: bridging the democratic gap?”. In: RIGGIROZZI, P.; TUSSIE, D. (eds.). The rise of post-hegemonic regionalism. The case of Latin America. Heidelberg/ London/New York: Springer. pp.147-66.

SOARES, M. R. S.; HIRST, M. 2006. Brazil as an intermediate State and regional power: action, choice and responsibilities. International Affairs, v.82, n.1, pp.21-40.

SPEKTOR, M. 2009. Brazil as a regional and emerging global power. Disponível em: <http://www.saiia.org.za/images/stories/pubs/briefings/saia_ spb_09_spektor_20091130.pdf>.

STOPFORD, J. M.; STRANGE, S. 1991. Rival States, rival firms, competition for world market shares. Cambridge: Cambridge University Press.

STRANGE, S. 1992. "States, firms and diplomacy". International Affairs, v.68, n.1, pp.1-15.

1975. "What is economic power and who has it?". International Journal, v.3, n.2, pp.207-24.

TRUCCO, P. 2012. "The rise of monetary agreements in South America”. In: RIGGIROZZI, P.; TUSSIE, D. (eds.). The rise of post-hegemonic regionalism. The case of Latin America. Heidelberg/London/New York: Springer. pp.101-24. 
Os imperativos do Brasil no desafiador espaço regional da América do Sul...

; TUSSIE, D. 2010. Nación y región en América del Sur: los actores nacionales y la economía política de la integración sudamericana. Buenos Aires: Editorial Teseo.

TUSSIE, D. 1991. "Trading in fear? US hegemony and the open world economy”. In: MURPHY, C.; TOOZE, R. (eds.). The new international political economy. Boulder, CO: Rienner.

VIGEVANI, T.; CEPALUNI, G. 2009. A política externa brasileira: a busca da autonomia de Sarney a Lula. São Paulo: Editora da Unesp.

VIOLA, E.; FRANCHINI, M.; RIBEIRO, T. L. R. 2012. “Climate governance in an international system under conservative hegemony: the role of major powers". Revista Brasileira de Política Internacional, v.55, pp.9-29. Disponível em: <http://www.scielo.br/scielo.php?pid=S003473292012000300002\&script=sci_arttext $>$.

WIENER, J. 1995. Making rules in the Uruguay Round of the GATT: a study of international leadership. Dartmouth: Aldershot. 


\section{OS IMPERATIVOS DO BRASIL NO DESAFIADOR ESPAÇO REGIONAL DA AMÉRICA DO SUL: UMA VISÃO DA ECONOMIA POLÍTICA INTERNACIONAL}

DIANA TUSSIE

Resumo: $\mathrm{O}$ artigo foca as bases econômicas e questiona se elas criam uma demanda de alcance regional e mundial da política externa. Com uma perspectiva integradora, quando se pensa em Estados, também se pensa em Estados e mercados díades. Quais são os interesses que circulam dentro dessa nova perspectiva? Se o debate sobre a construção regional significa ir além de uma construção narrativa, precisamos criar mais espaços para os incentivos que dirigem os atores, especialmente aqueles que estão se tornando cada vez mais integrados nas trocas globais. Em outras palavras, não é apenas o tamanho do país que importa, mas a intensidade e o conteúdo da integração na economia regional e mundial que importam no momento da construção regional. $\mathrm{O}$ artigo contém quatro seções. Em primeiro lugar, analisa-se como a economia política pode (ou deve) contribuir para o debate sobre o poder e a liderança em um hemisfério em mudança contínua. Em seguida, é discutido como alguns indicadores são aplicáveis aos interesses do Brasil como uma potência em ascensão. Depois, avalia-se a internacionalização das empresas brasileiras na região. Finalmente, discute-se o que essas tendências podem significar em termos de construção regional.

Palavras-chave: América do Sul; integração regional; Economia Política Internacional; Brasil.

\section{THE IMPERATIVES OF BRAZIL IN A CHALLENGING SOUTH AMERICAN REGIONAL SPACE: A VIEW FROM INTERNATIONAL POLITICAL ECONOMY}

Abstract: The article focuses on the economic bases and asks if these create a demand for regional and global outreach of foreign policy. 
With an integrative perspective, when one thinks of states one also thinks of the states and markets dyad. What are the inside interests that drive the new outlook? If the debate on region building is to go beyond a narrative construction we need to make greater room for the incentives that drive actors, especially those that are becoming increasingly integrated in global exchanges. In other words it is not only the size of the country that matters but the intensity and content of integration in the regional and world economy that matters at the time of region building. The article advances in four sections. I first review what political economy can (or should) contribute to the debate on power and leadership in a hemisphere in flux. In the following section, I discuss how some indicators are applicable to Brazilian interests as a rising power. Subsequently I analyze the internationalization of Brazilian business in the region and finally I discuss what these trends might mean in terms of region building.

Keywords: South America; Regional Integration; International Political Economy; Brazil.

Recebido: 02/05/2013 Aprovado: 15/08/2013 